\title{
Cardiometabolic Risk in Hyperlipidemic Men and Women
}

\author{
Michael Leutner, ${ }^{1}$ Christian Göbl, ${ }^{2}$ Alice Wielandner, ${ }^{3}$ Eleonora Howorka, ${ }^{1}$ \\ Marlies Prünner, ${ }^{1}$ Latife Bozkurt, ${ }^{4}$ Jürgen Harreiter, ${ }^{1}$ Helmut Prosch, ${ }^{3}$ \\ Oliver Schlager, ${ }^{5}$ Silvia Charwat-Resl, ${ }^{5}$ and Alexandra Kautzky-Willer ${ }^{1}$ \\ ${ }^{1}$ Department of Internal Medicine III, Division of Endocrinology and Metabolism, Unit of Gender Medicine, \\ Medical University of Vienna, Waehringer Guertel 18-20, 1090 Vienna, Austria \\ ${ }^{2}$ Department of Gynecology and Obstetrics, Division of Feto-Maternal Medicine, Medical University of Vienna, \\ Waehringer Guertel 18-20, 1090 Vienna, Austria \\ ${ }^{3}$ Department of Biomedical Imaging and Image Guided Therapy, Medical University of Vienna, \\ Waehringer Guertel 18-20, 1090 Vienna, Austria \\ ${ }^{4}$ Department of Internal Medicine III, Clinical Division of Endocrinology and Metabolism, Medical University of Vienna, \\ Waehringer Giertel 18-20, 1090 Vienna, Austria \\ ${ }^{5}$ Department of Internal Medicine II, Division of Angiology, Medical University of Vienna, \\ Waehringer Guertel 18-20, 1090 Vienna, Austria \\ Correspondence should be addressed to Alexandra Kautzky-Willer; alexandra.kautzky-willer@meduniwien.ac.at
}

Received 29 May 2016; Revised 4 October 2016; Accepted 9 October 2016

Academic Editor: Małgorzata Kotula-Balak

Copyright (C) 2016 Michael Leutner et al. This is an open access article distributed under the Creative Commons Attribution License, which permits unrestricted use, distribution, and reproduction in any medium, provided the original work is properly cited.

Objective. The aim of this study was to evaluate sex specific differences of metabolic and clinical characteristics of treated hyperlipidemic men and women (HL-men and HL-women). Methods. In this study vascular and metabolic characteristics of 35 HL-women and $64 \mathrm{HL}$-men were assessed. In addition a sex specific analysis of metabolic and nutritional habits of HL-patients with prediabetes (HL-IGR) was done. Results. HL-women were older and had favourable concentrations of high density lipoprotein cholesterol (HDL-cholesterol), triglycerides (TG), and triglyceride/HDL-cholesterol ratio (TG/HDL-ratio) but were also shown to have higher concentrations of lipoprotein-a compared to HL-men. HL-men were characterized as having higher levels of liverspecific parameters and body weight as well as being more physically active compared to HL-women. Brain natriuretic peptide (pro-BNP) was higher in HL-women than HL-men, while no differences in metabolic syndrome and glycemic parameters were shown. HL-IGR-women were also older and still had a better profile of sex specific lipid parameters, as well as a lower body weight compared to HL-IGR-men. No differences were seen in vascular parameters such as the intima media thickness (IMT). Conclusion. HL-women were older and had overall more favourable concentrations of lipid parameters and liver enzymes but did not differ regarding vascular morphology and insulin sensitivity compared to HL-men of comparable body mass index (BMI).

\section{Background}

In general men have a higher risk of cardiovascular mortality compared to women [1]. In addition to the better outcome in cardiovascular disease (CVD) in women, the time of occurrence of CVD is also later [2]. These discrepancies occur due to the significant influence that sex plays on the development of CVD [1].

One of the major influences on CVD is the lipid profile $[3,4]$ and it is well known that there are sex specific differences in the progression of CVD affected by hyperlipidemia $[5,6]$. In addition studies have shown that menopause and female sex hormones have a big influence on lipid parameters [7]. Studies show that there are also sex specific differences in the reach of target values of lipid parameters. Wenger showed that hyperlipidemic men reach more often the target values of blood parameters compared to women [8].

These discrepancies occur because there are multifactorial sex specific factors which influence the reach of target 
$[9,10]$. Nevertheless, dyslipidemic treatment reduces the occurrence of CVD in both sexes [11, 12].

In addition to dyslipidemia, prediabetes is also a risk factor for the development of CVD [13]. Studies show that women with high blood glucose levels have a higher risk of cardiovascular mortality compared to men [14-17].

Little is known about the combination of hyperlipidemia with hyperglycemia.

It was shown that there is a cumulative effect of hyperlipidemia and prediabetes on atherosclerosis and the development of coronary heart disease $[18,19]$.

Therefore, further investigations are necessary. The objective of this analysis is to compare the metabolic and clinic characteristics of hyperlipidemic men and women with and without prediabetes.

\section{Methods}

The detailed study procedures were previously described [18]. The primary outcome of this study was to compare sex specific differences in treated hyperlipidemic patients. We also studied sex differences in the high risk subgroup with prediabetes in this analysis.

In brief, this study included 35 women and 64 men with hyperlipidemia. The subanalysis of hyperlipidemic patients with prediabetes consisted of 19 women and 29 men. All patients were diagnosed and treated according to the ESC/EAS guidelines [20].

Prediabetes was diagnosed with glycated hemoglobin Alc (HbAlc) levels of $\geq 5.7 \%$ and $<6.5 \%$ or/and fasting glucose levels of $\geq 100 \mathrm{mg} / \mathrm{dL}$ and $<126 \mathrm{mg} / \mathrm{dL}$ according to the guidelines of the American Diabetes Association [21].

Inclusion criteria were an age between 35 and 75 years and a consistent dyslipidemic treatment (including diet), for at least the last three months before participating in the study. Patients with diabetes mellitus type- 1 or type- 2 were excluded from this study [18]. The study participants were divided into two groups according to sex.

Patients had a positive history of CVD if they had been diagnosed with one or more of the following: stroke, coronary heart disease, peripheral artery disease, myocardial infarction, or angina pectoris. Data from a 7-day food intake diary was used for the analysis of the mean daily energy intake (analysed with the program nut.s, nutritional software v1.32.37-2015.12.15, URL: http://www.nutritional-software.at/) in the specific subpopulation of HL-IGR-men and HL-IGRwomen. The medical history of the patients was assessed by a questionnaire and anthropometric data such as height, body weight, or waist circumference, as well as the blood pressure, were measured according to standardized procedures [18].

Physical activity was measured using an Omron Walking Style II pedometer. Therefore, study participants were instructed to take the pedometer for 7 days. After the 7 days the mean steps of the pedometer were calculated [18].

2.1. IMT Measurements. IMT measurements were performed by ultrasound and conducted by two experienced coinvestigators according to standardized procedures as previously described [18]. Measurements were obtained by using a $9 \mathrm{MHz}$ linear transducer probe of an Acuson ultrasound machine (Acuson XP 128, Siemens Medical Solutions, USA). IMT was measured by using frozen B-mode images of the far wall of the distal common carotid artery, approximately $1.5-2 \mathrm{~cm}$ proximal to the carotid bifurcation. In terms of reaching the values of "good clinical practice" the analysation process was blinded and performed under the supervision of an expert coinvestigator and by an experienced coinvestigator [18].

2.2. Laboratory Measurements. As previously described [18], laboratory parameters were taken in fasting conditions $(\geq 10$ hours) and measurements, including serum lipids, fasting plasma glucose, fasting insulin, C-peptide, $\mathrm{HbAlc}$, parameters of liver function, pro-BNP, and high sensitive CRP (hsCRP), were analysed according to international standard laboratory methods at the Department of Medical and Chemical Laboratory Diagnostics (http://www.kimcl.at/).

In accordance with the general guidelines the Friedewald formula was used for the assessment of low density lipoprotein cholesterol (LDL-cholesterol) [22].

2.3. Calculations. We measured insulin sensitivity by using the QUICKI-test [23].

2.4. Statistical Analysis. Means \pm standard deviations were stated for normal continuous variables and percentages for categorical variables. Median and interquartile range were stated if variables were not normally distributed (verification with the Shapiro-Wilk-test).

Students $t$-test and Fisher's exact test were applied for sex specific group comparisons (men versus women). If normality assumption was not given, Wilcoxon rank sum test was used for group based comparisons. Logarithmic transformation was used for parameters which were strongly skewed: $\ln (\mathrm{TG}), \ln (\mathrm{TG} / \mathrm{HDL}-$ ratio), $\ln$ (lipoprotein-a), $\ln ($ insulin +1$), \ln ($ pro-BNP), $\ln ($ hsCRP+1), $\ln$ (glutamate-oxaloacetate transaminase, GOT), $\ln$ (glutamate-pyruvate transaminase, GPT), and $\ln$ (gamma-glutamyl transferase, GGT). Pearson's product moment correlation was used for the analysis of correlations between continuous variables.

In the case of multivariable adjustment linear two-way ANOVA models (modeling interactions between sex and prediabetes on lipid parameters) were used.

Power analysis was performed to determine the sample size needed to achieve $80 \%$ test power for the $t$-test analyses. This analysis was performed using $\mathrm{G}^{*}$ Power software, version 3.1.9.2 (software freely available from the University of Düsseldorf). For fasting glucose, a mean difference of $10 \mathrm{mg} / \mathrm{dL}$ and a standard deviation of $14 \mathrm{mg} / \mathrm{dL}$ were assumed as clinically relevant. Therefore the minimal sample size was calculated as 32 patients per group. For LDL-cholesterol, for a mean difference of $30 \mathrm{mg} / \mathrm{dL}$ and assumed standard deviation of $40 \mathrm{mg} / \mathrm{dL}$, the minimal sample size was calculated as 29 patients per group.

The statistical analysis was done with R (V3.1.1) [24]. Statistical significance was assumed with a two-sided $p$ value of $\leq 0.05$. 
TABLE 1: Characteristics of the study sample, divided by sex.

\begin{tabular}{|c|c|c|c|c|}
\hline & $n$ (female/male) & Female & Male & $p$ value \\
\hline Age [years] ${ }^{*}$ & $35 / 64$ & $58.0 \pm 10.8$ & $50.4 \pm 9.3$ & 0.001 \\
\hline BMI $\left[\mathrm{kg} / \mathrm{m}^{2}\right]^{*}$ & $34 / 61$ & $27.7 \pm 5.5$ & $27.7 \pm 3.5$ & 0.998 \\
\hline Body weight & $34 / 61$ & $72.99 \pm 13.72$ & $88.47 \pm 12.62$ & $<0.001$ \\
\hline Waist $[\mathrm{cm}]^{*}$ & $31 / 58$ & $91.8 \pm 11.6$ & $98.7 \pm 12.2$ & 0.011 \\
\hline $\mathrm{RRS}[\mathrm{mmHg}]^{*}$ & $24 / 45$ & $125.9 \pm 14.4$ & $132.2 \pm 14.8$ & 0.089 \\
\hline $\mathrm{RRD}[\mathrm{mmHg}]^{*}$ & $24 / 45$ & $78.5 \pm 8.7$ & $81.8 \pm 10.4$ & 0.162 \\
\hline $\mathrm{TC}[\mathrm{mg} / \mathrm{dL}]^{*}$ & $35 / 64$ & $243.9 \pm 72.3$ & $227.6 \pm 74.1$ & 0.290 \\
\hline LDL-C $[\mathrm{mg} / \mathrm{dL}]^{*}$ & $34 / 60$ & $143.3 \pm 59.2$ & $127.1 \pm 45.6$ & 0.174 \\
\hline LDL-C $<100 \mathrm{mg} / \mathrm{dL}$ & $34 / 60$ & $9(26.5 \%)$ & $17(28.3 \%)$ & 0.911 \\
\hline $\mathrm{HDL}-\mathrm{C}[\mathrm{mg} / \mathrm{dL}]^{*}$ & $33 / 60$ & $65.2 \pm 19.6$ & $45.0 \pm 15.1$ & $<0.001$ \\
\hline NHDL-C $[\mathrm{mg} / \mathrm{dL}]^{*}$ & $33 / 60$ & $173.1 \pm 61.5$ & $172.2 \pm 59.3$ & 0.947 \\
\hline $\ln (\mathrm{TG})[\mathrm{mg} / \mathrm{dL}]^{*}$ & $35 / 64$ & $5.1 \pm 0.64$ & $5.53 \pm 0.82$ & 0.008 \\
\hline $\ln (\mathrm{TG} / \mathrm{HDL})^{*}$ & $33 / 60$ & $0.89 \pm 0.7$ & $1.65 \pm 0.87$ & $<0.001$ \\
\hline $\ln \left(\right.$ Lip.a) [units] ${ }^{*}$ & $30 / 57$ & $3.5 \pm 1.05$ & $2.94 \pm 1.22$ & 0.031 \\
\hline 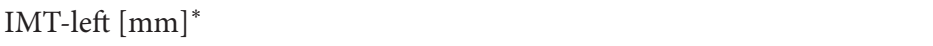 & $31 / 58$ & $0.65 \pm 0.18$ & $0.63 \pm 0.14$ & 0.584 \\
\hline IMT-right $[\mathrm{mm}]^{*}$ & $30 / 56$ & $0.64 \pm 0.15$ & $0.63 \pm 0.12$ & 0.824 \\
\hline IMT av $[\mathrm{mm}]^{*}$ & $30 / 56$ & $0.64 \pm 0.14$ & $0.63 \pm 0.12$ & 0.711 \\
\hline Glucose $[\mathrm{mg} / \mathrm{dL}]^{*}$ & $34 / 61$ & $93.4 \pm 10.8$ & $94.2 \pm 10.7$ & 0.720 \\
\hline $\ln ($ insulin +1$)[\mu \mathrm{U} / \mathrm{mL}]^{*}$ & $32 / 60$ & $2.05 \pm 0.69$ & $2.28 \pm 0.67$ & 0.131 \\
\hline C-peptide $[\mathrm{ng} / \mathrm{mL}]^{*}$ & $28 / 50$ & $2.91 \pm 2.07$ & $2.65 \pm 1.11$ & 0.546 \\
\hline HbAlc $[\%]^{*}$ & $35 / 62$ & $5.61 \pm 0.37$ & $5.46 \pm 0.38$ & 0.054 \\
\hline QUICKI-test* & $29 / 49$ & $0.37 \pm 0.05$ & $0.35 \pm 0.04$ & 0.266 \\
\hline $\ln \left(\right.$ proBNP) [units] ${ }^{*}$ & $30 / 55$ & $4.57 \pm 0.79$ & $3.77 \pm 1.20$ & $<0.001$ \\
\hline $\ln ($ hsCRP +1$)\left[\right.$ units] ${ }^{*}$ & $30 / 62$ & $0.30 \pm 0.28$ & $0.21 \pm 0.21$ & 0.161 \\
\hline $\ln (\mathrm{GOT})[\mathrm{mg} / \mathrm{dL}]^{*}$ & $34 / 64$ & $3.29 \pm 0.37$ & $3.38 \pm 0.35$ & 0.263 \\
\hline $\ln (\mathrm{GPT})[\mathrm{mg} / \mathrm{dL}]^{*}$ & $34 / 64$ & $3.22 \pm 0.47$ & $3.46 \pm 0.47$ & 0.021 \\
\hline $\ln (\mathrm{GGT})[\mathrm{mg} / \mathrm{dL}]^{*}$ & $34 / 64$ & $3.28 \pm 0.76$ & $3.79 \pm 0.82$ & 0.003 \\
\hline Prediabetes $^{* *}$ & $34 / 62$ & $19(55.9)$ & $29(46.8)$ & 0.522 \\
\hline Ezetimibe $^{* *}$ & $33 / 55$ & $3(9.1)$ & $6(10.9)$ & 1.000 \\
\hline Nicotinic acid ${ }^{* *}$ & $33 / 54$ & $1(3.0)$ & $4(7.4)$ & 0.646 \\
\hline Fibrates $^{* *}$ & $33 / 54$ & $5(15.2)$ & $22(40.7)$ & 0.017 \\
\hline Statins ${ }^{* *}$ & $33 / 54$ & $16(48.5)$ & $38(70.4)$ & 0.068 \\
\hline $\mathrm{CVD}^{* *}$ & $33 / 60$ & $2(6.1)$ & $10(16.7)$ & 0.202 \\
\hline Mean steps 7 days* & $31 / 47$ & $7230.2 \pm 2106.1$ & $8500.1 \pm 3395.9$ & 0.045 \\
\hline Metabolic syndrome ${ }^{* *}$ & $21 / 44$ & $7(33.3)$ & $16(36.4)$ & 1.000 \\
\hline Mean treatment duration of the last taken dyslipidemic medication (days)* & $33 / 62$ & $2068.03 \pm 2635.61$ & $1879.77 \pm 1997.47$ & 0.721 \\
\hline
\end{tabular}

${ }^{*} t$-test, ${ }^{* *}$ Chi-square test.

Data are presented as number of observations $(n)$ and means \pm standard deviation. BMI (body mass index), waist (waist circumference), RRS (systolic blood pressure), RRD (diastolic blood pressure), TC (total cholesterol), LDL-C (low density lipoprotein cholesterol), HDL-C (high density lipoprotein cholesterol), NHDL-C (non-high density lipoprotein cholesterol), TG (triglycerides), TG/HDL (triglyceride/HDL-cholesterol ratio), Lip.a (lipoprotein (a)), IMT (carotid intima media thickness), HbAlc (glycated hemoglobin Alc), QUICKI (quantitative insulin sensitivity check index), proBNP (pro B-type natriuretic peptide), hsCRP (high sensitive C-reactive protein), GOT (glutamate-oxaloacetate transaminase), GPT (glutamate-pyruvate transaminase), GGT (gamma-glutamyl transferase), and CVD (cardiovascular disease).

\section{Results}

In this study $35 \mathrm{HL}$-women and $64 \mathrm{HL}$-men were included. A descriptive comparison of study participants, divided by sex, is shown in Table 1 . This table shows that HLwomen were older and had a lower body weight and waist circumference but did not differ regarding BMI and the systolic and diastolic blood pressure compared to HL-men. HL-women were shown to have better concentrations of lipid parameters such as HDL-cholesterol, TG, and TG/HDL-ratio but had higher concentrations of lipoprotein-a compared to HL-men (Table 1). No sex specific difference was shown in the occurrence of LDL-cholesterol levels $<100 \mathrm{mg} / \mathrm{dL}$. Univariable comparisons showed that there was no significant difference in carotid IMT measurements between HL-men and HL-women. In addition, no sex specific differences in the glucose metabolism (glucose, insulin, C-peptide, HbAlc, and QUICKI-test) were found. HL-women were also shown to have higher levels of traditional cardiovascular risk marker pro-BNP, but not hs-CRP (Table 1). 
TABLE 2: Characteristics of the study sample with prediabetes, divided by sex.

\begin{tabular}{|c|c|c|c|c|}
\hline & $n$ (female/male) & Female & Male & $p$ value \\
\hline Age [years] ${ }^{*}$ & $19 / 29$ & $62.4 \pm 9.6$ & $54.4 \pm 9.8$ & 0.007 \\
\hline Body weight & $19 / 28$ & $73.50 \pm 13.62$ & $90.49 \pm 13.55$ & $<0.001$ \\
\hline BMI $\left[\mathrm{kg} / \mathrm{m}^{2}\right]^{*}$ & $19 / 28$ & $27.8 \pm 4.8$ & $28.9 \pm 3.7$ & 0.360 \\
\hline Waist $[\mathrm{cm}]^{*}$ & $18 / 27$ & $94.9 \pm 9.2$ & $104.4 \pm 8.9$ & 0.001 \\
\hline $\mathrm{RRS}[\mathrm{mmHg}]^{*}$ & $14 / 20$ & $127.5 \pm 17.6$ & $136.4 \pm 18.2$ & 0.164 \\
\hline $\mathrm{RRD}[\mathrm{mmHg}]^{*}$ & $14 / 20$ & $77.2 \pm 10.7$ & $82.1 \pm 11.5$ & 0.223 \\
\hline $\mathrm{TC}[\mathrm{mg} / \mathrm{dL}]^{*}$ & $19 / 29$ & $238.6 \pm 68.3$ & $231.6 \pm 81.5$ & 0.371 \\
\hline $\mathrm{LDL}-\mathrm{C}[\mathrm{mg} / \mathrm{dL}]^{*}$ & $18 / 27$ & $136.2 \pm 50.2$ & $131.5 \pm 45.4$ & 0.746 \\
\hline $\mathrm{HDL}-\mathrm{C}[\mathrm{mg} / \mathrm{dL}]^{*}$ & $17 / 27$ & $62.7 \pm 16.1$ & $43.7 \pm 14.6$ & $<0.001$ \\
\hline NHDL-C $[\mathrm{mg} / \mathrm{dL}]^{*}$ & $17 / 27$ & $164.3 \pm 47.4$ & $171.5 \pm 50.5$ & 0.640 \\
\hline $\ln (\mathrm{TG})[\mathrm{mg} / \mathrm{dL}]^{*}$ & $19 / 29$ & $5.2 \pm 0.69$ & $5.55 \pm 0.76$ & 0.165 \\
\hline $\ln (\mathrm{TG} / \mathrm{HDL})^{*}$ & $17 / 27$ & $0.97 \pm 0.66$ & $1.70 \pm 0.81$ & 0.003 \\
\hline $\ln \left(\right.$ Lip.a) [units] ${ }^{*}$ & $17 / 26$ & $4.00 \pm 1.04$ & $2.96 \pm 1.40$ & 0.013 \\
\hline 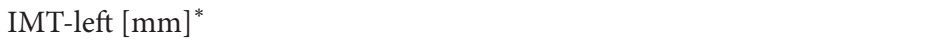 & $17 / 26$ & $0.68 \pm 0.18$ & $0.69 \pm 0.17$ & 0.576 \\
\hline IMT-right $[\mathrm{mm}]^{*}$ & $17 / 26$ & $0.69 \pm 0.16$ & $0.66 \pm 0.14$ & 0.463 \\
\hline IMT av $[\mathrm{mm}]^{*}$ & $17 / 26$ & $0.69 \pm 0.15$ & $0.68 \pm 0.14$ & 0.834 \\
\hline Glucose $[\mathrm{mg} / \mathrm{dL}]^{*}$ & $19 / 27$ & $99.8 \pm 9.2$ & $100.3 \pm 12.0$ & 0.882 \\
\hline $\ln ($ insulin +1$)[\mu \mathrm{U} / \mathrm{mL}]^{*}$ & $17 / 27$ & $2.15 \pm 0.77$ & $2.41 \pm 0.75$ & 0.273 \\
\hline C-peptide $[\mathrm{ng} / \mathrm{mL}]^{*}$ & $16 / 23$ & $3.44 \pm 2.55$ & $3.03 \pm 1.16$ & 0.656 \\
\hline HbAlc $[\%]^{*}$ & $19 / 28$ & $5.83 \pm 0.32$ & $5.73 \pm 0.33$ & 0.322 \\
\hline QUICKI-test ${ }^{*}$ & $16 / 23$ & $0.36 \pm 0.05$ & $0.35 \pm 0.05$ & 0.478 \\
\hline $\ln \left(\right.$ proBNP) [units] ${ }^{*}$ & $16 / 23$ & $4.18 \pm 0.61$ & $4.23 \pm 1.51$ & 0.905 \\
\hline $\ln (\mathrm{hsCRP}+1)$ [units] & $17 / 28$ & $0.30 \pm 0.29$ & $0.20 \pm 0.17$ & 0.440 \\
\hline $\ln (\mathrm{GOT})[\mathrm{mg} / \mathrm{dL}]^{*}$ & $18 / 29$ & $3.34 \pm 0.35$ & $3.41 \pm 0.37$ & 0.499 \\
\hline $\ln (\mathrm{GPT})[\mathrm{mg} / \mathrm{dL}]^{*}$ & $18 / 29$ & $3.32 \pm 0.45$ & $3.55 \pm 0.46$ & 0.098 \\
\hline $\ln (\mathrm{GGT})[\mathrm{mg} / \mathrm{dL}]^{*}$ & $18 / 29$ & $3.52 \pm 0.78$ & $3.96 \pm 0.70$ & 0.048 \\
\hline Ezetimibe $^{* *}$ & $19 / 23$ & $2(10.5)$ & $3(13.0)$ & 1.000 \\
\hline Nicotinic acid ${ }^{* *}$ & $19 / 23$ & $0(0.0)$ & $2(8.7)$ & 0.556 \\
\hline Fibrates $^{* *}$ & $19 / 23$ & $2(10.5)$ & $9(39.1)$ & 0.081 \\
\hline Statins ${ }^{* *}$ & $19 / 23$ & $11(57.9)$ & $19(82.6)$ & 0.155 \\
\hline $\mathrm{CVD}^{* *}$ & $18 / 27$ & $1(5.6)$ & $8(29.6)$ & 0.110 \\
\hline Mean steps 7 days* & $17 / 21$ & $7009.8 \pm 2520.4$ & $8381.4 \pm 2660.0$ & 0.114 \\
\hline Metabolic syndrome ${ }^{* *}$ & $12 / 20$ & $5(41.7)$ & $12(60.0)$ & 0.522 \\
\hline Mean treatment duration of the last taken dyslipidemic medication (days) ${ }^{*}$ & $18 / 28$ & $2272.3 \pm 2649.9$ & $2132.8 \pm 2362.1$ & 0.938 \\
\hline
\end{tabular}

${ }^{*} t$-test, ${ }^{* *}$ Chi-square test.

Data are presented as number of observations $(n)$ and means \pm standard deviation. BMI (body mass index), waist (waist circumference), RRS (systolic blood pressure), RRD (diastolic blood pressure), TC (total cholesterol), LDL-C (low density lipoprotein cholesterol), HDL-C (high density lipoprotein cholesterol), NHDL-C (non-high density lipoprotein cholesterol), TG (triglycerides), TG/HDL (triglyceride/HDL-cholesterol ratio), Lip.a (lipoprotein (a)), IMT (carotid intima media thickness), HbAlc (glycated hemoglobin Alc), QUICKI (quantitative insulin sensitivity check index), proBNP (pro B-type natriuretic peptide), hsCRP (high sensitive C-reactive protein), GOT (glutamate-oxaloacetate transaminase), GPT (glutamate-pyruvate transaminase), GGT (gamma-glutamyl transferase), and CVD (cardiovascular disease).

HL-men in this study were characterized as being more physically active (mean steps in 7 days) and as having significantly higher liver-specific parameters (GGT, GPT). No sex specific differences were observed in the occurrence of a history of CVD and of the metabolic syndrome (Table 1).

\section{Sex Specific Subanalysis of HL-Patients with Prediabetes Including Nutritional Data}

In addition to the analysis above, a subanalysis of 19 women and 29 men with hyperlipidemia additionally affected by a prediabetes was done. A descriptive comparison of study participants, divided by sex, is shown in Table 2 .

This table shows that HL-IGR-women were older and had a lower body weight and waist circumference but did not differ in other anthropometric parameters such as BMI and the systolic and diastolic blood pressure compared to HL-IGR-men. There was no significant difference in modifiable lipid parameters (total cholesterol, LDLcholesterol, and TG) between sexes. HL-IGR-women were shown to have significantly higher levels of HDL-cholesterol and lipoprotein-a, as well as favourable concentrations of 
TABLE 3: Nutritional characteristics of the study sample with prediabetes, divided by sex.

\begin{tabular}{|c|c|c|c|c|}
\hline & $n$ (female/male) & Female & Male & $p$ value \\
\hline Total energy intake (kcal) ${ }^{*}$ & $14 / 20$ & $1386.6 \pm 388.9$ & $1790.0 \pm 693.6$ & 0.104 \\
\hline Fat $(\mathrm{mg})^{*}$ & $14 / 20$ & $53456.7 \pm 20456.9$ & $61750.4 \pm 30408.8$ & 0.381 \\
\hline Cholesterol (mg) ${ }^{*}$ & $14 / 20$ & $207 \pm 99.4$ & $297.4 \pm 153.9$ & 0.063 \\
\hline Omega-3 fatty acids (mg) ${ }^{*}$ & $14 / 20$ & $1700.8 \pm 978.5$ & $1767.6 \pm 1032.6$ & 0.796 \\
\hline Omega- 6 fatty acids $(\mathrm{mg})^{*}$ & $14 / 20$ & $7807.6 \pm 3722.0$ & $8100.2 \pm 3762.5$ & 0.824 \\
\hline Polyunsaturated fatty acids $(\mathrm{mg})^{*}$ & $14 / 20$ & $9511.2 \pm 4487.1$ & $10284.0 \pm 4786.2$ & 0.638 \\
\hline Saturated fatty acids $(\mathrm{mg})^{*}$ & $14 / 20$ & $22987.7 \pm 10056.8$ & $27342.2 \pm 13537.4$ & 0.315 \\
\hline Monounsaturated fatty acids (mg) ${ }^{*}$ & $14 / 20$ & $17529.6 \pm 6988.6$ & $29249.2 \pm 30968.1$ & 0.097 \\
\hline Carbohydrates $(\mathrm{mg})^{*}$ & $14 / 20$ & $157769.7 \pm 40805.0$ & $177359.1 \pm 79750.7$ & 0.356 \\
\hline Disaccharides $(\mathrm{mg})^{*}$ & $14 / 20$ & $38443.8 \pm 18889.7$ & $35274.7 \pm 25976.0$ & 0.457 \\
\hline Lactose $(\mathrm{mg})^{*}$ & $14 / 20$ & $7232.8 \pm 8305.5$ & $6326.8 \pm 7283.3$ & 0.738 \\
\hline Sucrose $(\mathrm{mg})^{*}$ & $14 / 20$ & $30101.6 \pm 12942.5$ & $28658.6 \pm 23784.8$ & 0.416 \\
\hline Monosaccharides $(\mathrm{mg})^{*}$ & $14 / 20$ & $26831.4 \pm 10530.5$ & $27196.4 \pm 17224.5$ & 0.944 \\
\hline Fructose $(\mathrm{mg})^{*}$ & $14 / 20$ & $15225.3 \pm 6670.6$ & $14812.5 \pm 9728.1$ & 0.892 \\
\hline Glucose $(\mathrm{mg})^{*}$ & $14 / 20$ & $11032.1 \pm 3862.8$ & $11869.7 \pm 7680.7$ & 0.679 \\
\hline Glycogen (mg)* & $14 / 20$ & $33.6 \pm 56.1$ & $239.0 \pm 255.9$ & 0.001 \\
\hline $\operatorname{Vitamin} \mathrm{B} 12(\mu \mathrm{g})^{*}$ & $14 / 19$ & $3.0 \pm 1.6$ & $4.6 \pm 1.9$ & 0.011 \\
\hline Dietary fiber (mg) ${ }^{*}$ & $14 / 20$ & $18009.2 \pm 5366.7$ & $20243.3 \pm 10600.1$ & 0.904 \\
\hline Protein $(\mathrm{mg})^{*}$ & $14 / 19$ & $55761.9 \pm 20497.3$ & $77520.9 \pm 27476.4$ & 0.018 \\
\hline
\end{tabular}

${ }^{*} t$-test.

Data are presented as number of observations $(n)$ and means \pm standard deviation.

TG/HDL-ratio compared to HL-IGR-men. No difference was found in carotid IMT measurements between HL-IGRmen and HL-IGR-women. In addition, no differences in glucose metabolism (glucose, insulin, C-peptide, HbAlc, and QUICKI-test) and in cardiovascular risk markers (pro-BNP, hsCRP) between sexes were found in this specific subanalysis (Table 2).

HL-IGR-men were shown to have higher liver-specific parameters (GGT, Table 2). Table 3 shows that glycogen, vitamin-B12, and protein intake, measured with a dietary protocol, were significantly higher in HL-IGR-men.

As shown in Table 4 sex specific analyses revealed that waist circumference is related to concentrations of TG in HL-IGR-women, but not in HL-IGR-men. No association with waist circumference was observed for any other lipid parameters (LDL-cholesterol, HDL-cholesterol, total cholesterol, and TG in men) or parameters of glucose metabolism (fasting plasma glucose, $\mathrm{HbAlc}$ ) in both sexes. In addition no correlation of waist circumference with IMT in both sexes was found. Table 4 also shows that there was no association for body weight and BMI with lipid parameters and parameters of glucose metabolism in HL-IGR-men and HL-IGR-women. In general no interactions between sex and prediabetes with lipid parameters (LDL-cholesterol, HDLcholesterol, TG, and total cholesterol) were found.

\section{Discussion}

HL-women are characterized as being older and having a lower body weight and waist circumference, more favourable concentrations of HDL-cholesterol, TG, and TG/HDL-ratio, and better concentrations of liver enzymes, but they do not differ regarding insulin sensitivity and the IMT compared to HL-men. The metabolic characteristics of HL-IGR-men and HL-IGR-women are in general comparable with the metabolic characteristics of the whole study population.

The fact that HL-women have favourable concentrations of certain lipid parameters (HDL-cholesterol, TG/HDLratio) is a well described sex specific difference in various conditions. In general men have a higher risk of CVD compared to women [1]. The higher levels of HDL-cholesterol in women are one of the major protective factors against developing CVD, which leads to a later occurrence of cardiovascular disease in women [2]. Female sex hormones relate to higher HDL-cholesterol levels in women and exert overall protective effects against CVD $[25,26]$. In our study population there were no significant sex specific differences in modifiable lipid parameters, such as LDL-cholesterol or total cholesterol. Only the concentrations of TG were shown to be significantly lower in female participants. This is an interesting point because studies showed that women were less likely to reach treatment goals of lipid parameters compared to men [2729]. So the similarity of lipid parameters, such as LDLcholesterol or total cholesterol between the sexes in our study, could point out that the previously described sex specific differences in reach of target values of lipid parameters faded. To support this hypothesis our results showed that there is no sex specific difference in the presence of LDL-cholesterol levels $<100 \mathrm{mg} / \mathrm{dL}$ in this study. The fact that HL-women have higher concentrations of cardiovascular risk marker pro-BNP could point to a higher risk for CVD. Wang et al. showed that women have in general higher concentrations of natriuretic peptide (NP) [30], which positively correlate with estrogen concentrations [31, 32]. Lam et al. also showed 
TABLE 4: Correlation analysis of parameters of body composition with cardiovascular and metabolic characteristics divided by sex in HLIGR-patients.

\begin{tabular}{|c|c|c|c|c|c|c|}
\hline & \multicolumn{2}{|c|}{ Body weight } & \multicolumn{2}{|c|}{ BMI } & \multicolumn{2}{|c|}{ Waist circumference } \\
\hline & rho & $p$ value & rho & $p$ value & rho & $p$ value \\
\hline \multicolumn{7}{|l|}{$H L-I G R-m e n$} \\
\hline LDL-cholesterol & -0.10 & NS & -0.13 & NS & -0.10 & NS \\
\hline HDL-cholesterol & -0.14 & NS & -0.19 & NS & -0.04 & NS \\
\hline Total cholesterol & -0.00 & NS & -0.05 & NS & -0.03 & NS \\
\hline Triglycerides & 0.16 & NS & 0.23 & NS & 0.06 & NS \\
\hline HbAlc & -0.00 & NS & -0.13 & NS & 0.17 & NS \\
\hline Fasting plasma glucose & 0.08 & NS & 0.01 & NS & 0.18 & NS \\
\hline \multicolumn{7}{|l|}{ HL-IGR-women } \\
\hline LDL-cholesterol & -0.11 & NS & -0.14 & NS & -0.01 & NS \\
\hline HDL-cholesterol & -0.24 & NS & -0.21 & NS & -0.07 & NS \\
\hline Total cholesterol & -0.09 & NS & -0.07 & NS & 0.06 & NS \\
\hline Triglycerides & 0.35 & NS & 0.36 & NS & 0.49 & 0.04 \\
\hline HbAlc & -0.02 & NS & 0.25 & NS & 0.11 & NS \\
\hline Fasting plasma glucose & 0.10 & NS & 0.16 & NS & 0.33 & NS \\
\hline
\end{tabular}

that women in menopause have still higher concentrations of NP compared to men. Additionally they showed that testosterone has a decreasing effect on the concentrations of NP in men [33]. Nevertheless Kannel showed that women in the postmenopausal status have a significant increase in the development of CVD [34]. So larger and longitudinal studies are required in order to find conclusive results, whether the higher concentration of pro-BNP is due to sex hormones in this specific population.

In general the metabolic characterization of the high risk population of HL-IGR-women and men is comparable with the results of the whole study population above.

Although there were not any significant sex specific differences in traditional cardiovascular risk markers in the specific population of HL-IGR-patients, it can be speculated that the cohort of HL-IGR-women is at higher risk for mortality compared to HL-IGR-men because in addition to hyperlipidemia, hyperglycemia is, especially in women, a higher risk factor for cardiovascular mortality compared to men [15-17].

Therefore, it has to be reported that atherogenic dyslipidemia, including reduced levels of HDL-cholesterol and increased levels of small dense LDL particles and triglycerides, is a feature of prediabetes. This interrelationship between impaired glucose regulation and lipid abnormalities leads in further consequence to an increased risk of developing CVD, indicating that HL-IGR-patients could be a high risk population [35].

Despite the lack of significance regarding the occurrence of CVD, men showed a higher occurrence rate $(29.6 \%)$ compared to women (5.6\%) in this study. This number seems to be plausible because men have in general a higher risk of developing CVD [1] with an earlier onset [2]. Nevertheless the specific subpopulation of treated HL-IGR-women around menopause could be a high risk population which should be monitored and treated to target more thoroughly. Interestingly in our study it was shown that there is a positive correlation of triglycerides with waist circumference in HLIGR-women, but not in men. So an adverse body composition could be a higher risk factor for metabolic diseases in HL-IGR-women. Therefore, larger studies are required to investigate these sex specific differences.

One major limitation of this study is the low number of participants and that prediabetes was diagnosed using fasting blood parameters and not the oral glucose tolerance test. In addition the difference in the mean ages is a further limitation.

We are aware that with our study design smaller effects could have been missed. This study has an exploratory character and should show the sex specific cardiometabolic characteristics in the specific population of treated hyperlipidemic men and women. Nevertheless a greater number of study participants would be needed in order to investigate the real risk of this specific population.

In conclusion HL-women were older and had overall more favourable concentrations of lipid parameters and liver enzymes but did not differ regarding vascular morphology and insulin sensitivity compared to men of comparable BMI. Nevertheless the age of menopause could be a major risk factor for CVD. So HL-women, especially after menopause, should be treated and observed more carefully, not only regarding hyperlipidemia, but also regarding hyperglycemia. Larger studies should be done in order to evaluate the real risk of this specific subpopulation.

\section{Competing Interests}

The authors have no competing interests.

\section{References}

[1] P. Jousilahti, E. Vartiainen, J. Tuomilehto, and P. Puska, "Sex, age, cardiovascular risk factors, and coronary heart disease: a prospective follow-up study of 14786 middle-aged men and 
women in Finland," Circulation, vol. 99, no. 9, pp. 1165-1172, 1999.

[2] W. P. Castelli, "Epidemiology of coronary heart disease: The Framingham Study," The American Journal of Medicine, vol. 76, no. 2, pp. 4-12, 1984.

[3] J. E. Hokanson and M. A. Austin, "Plasma triglyceride level is a risk factor for cardiovascular disease independent of high-density lipoprotein cholesterol level: a meta-analysis of population-based prospective studies," Journal of Cardiovascular Risk, vol. 3, no. 2, pp. 213-219, 1996.

[4] T. Gordon, W. P. Castelli, M. C. Hjortland, W. B. Kannel, and T. R. Dawber, "High density lipoprotein as a protective factor against coronary heart disease. The Framingham study," The American Journal of Medicine, vol. 62, no. 5, pp. 707-714, 1977.

[5] G. Hu, "Gender difference in all-cause and cardiovascular mortality related to hyperglycaemia and newly-diagnosed diabetes," Diabetologia, vol. 46, no. 5, pp. 608-617, 2003.

[6] J. Perk, G. De Backer, H. Gohlke et al., "European guidelines on cardiovascular disease prevention in clinical practice (version 2012). The Fifth Joint Task Force of the European Society of Cardiology and Other Societies on Cardiovascular Disease Prevention in Clinical Practice (constituted by representatives of nine societies and by invited experts)," European Heart Journal, vol. 33, no. 13, pp. 1635-701, 2012.

[7] R. D. Gambrell Jr. and A.-Z. Teran, "Changes in lipids and lipoproteins with long-term estrogen deficiency and hormone replacement therapy," American Journal of Obstetrics \& Gynecology, vol. 165, no. 2, pp. 307-317, 1991.

[8] N. K. Wenger, "Lipid abnormalities in women: data for risk, data for management," Cardiology in Review, vol. 14, no. 6, pp. 276280, 2006.

[9] D. J. Harris and P. S. Douglas, "Enrollment of women in cardiovascular clinical trials funded by the National Heart, Lung, and Blood Institute," The New England Journal of Medicine, vol. 343, no. 7, pp. 475-480, 2000.

[10] L. A. Blauwet and R. F. Redberg, "The role of sex-specific results reporting in cardiovascular disease," Cardiology in Review, vol. 15, no. 6, pp. 275-278, 2007.

[11] L. Mosca, E. J. Benjamin, K. Berra et al., "Effectivenessbased guidelines for the prevention of cardiovascular disease in women-2011 update: a guideline from the American Heart Association," Circulation, vol. 123, no. 11, pp. 1243-1262, 2011.

[12] S. Mora, R. J. Glynn, J. Hsia, J. G. MacFadyen, J. Genest, and P. M. Ridker, "Statins for the primary prevention of cardiovascular events in women with elevated high-sensitivity C-reactive protein or dyslipidemia: results from the Justification for the Use of Statins in Prevention: an Intervention Trial Evaluating Rosuvastatin (JUPITER) and meta-analysis of women from primary prevention trials," Circulation, vol. 121, no. 9, pp. 10691077, 2010.

[13] E. S. Ford, G. Zhao, and C. Li, "Pre-diabetes and the risk for cardiovascular disease: a systematic review of the evidence," Journal of the American College of Cardiology, vol. 55, no. 13, pp. 1310-1317, 2010.

[14] W.-H. Pan, L. B. Cedres, K. Liu et al., "Relationship of clinical diabetes and asymptomatic hyperglycemia to risk of coronary heart disease mortality in men and women," American Journal of Epidemiology, vol. 123, no. 3, pp. 504-516, 1986.

[15] DECODE Study Group and The European Diabetes Epidemiology Group, "Glucose tolerance and cardiovascular mortality: comparison of fasting and 2-hour diagnostic criteria," Archives of Internal Medicine, vol. 161, no. 3, pp. 397-405, 2001.
[16] T. J. Orchard, "The impact of gender and general risk factors on the occurrence of atherosclerotic vascular disease in noninsulin-dependent diabetes mellitus," Annals of Medicine, vol. 28, no. 4, pp. 323-333, 1996.

[17] W. L. Lee, A. M. Cheung, D. Cape, and B. Zinman, "Impact of diabetes on coronary artery disease in women and men: a metaanalysis of prospective studies," Diabetes Care, vol. 23, no. 7, pp. 962-968, 2000.

[18] M. Leutner, C. Göbl, A. Wielandner et al., "Clinical and metabolic characteristics of treated hyperlipidemic patients additionally affected by subclinical hyperglycemia," Lipids in Health and Disease, vol. 15, article 10, 2016.

[19] A. Fontbonne, E. Eschwège, F. Cambien et al., "Hypertriglyceridaemia as a risk factor of coronary heart disease mortality in subjects with impaired glucose tolerance or diabetes. Results from the 11-year follow-up of the Paris Prospective Study," Diabetologia, vol. 32, no. 5, pp. 300-304, 1989.

[20] Z. Reiner, A. L. Catapano, G. De Backer et al., "ESC/EAS Guidelines for the management of dyslipidaemias: the Task Force for the management of dyslipidaemias of the European Society of Cardiology (ESC) and the European Atherosclerosis Society (EAS)," European Heart Journal, vol. 32, no. 14, pp. 17691818, 2011.

[21] American Diabetes Association, "Diagnosis and classification of diabetes mellitus," Diabetes Care, vol. 35, supplement 1, pp. S64-S71, 2012.

[22] W. T. Friedewald, R. I. Levy, and D. S. Fredrickson, "Estimation of the concentration of low-density lipoprotein cholesterol in plasma, without use of the preparative ultracentrifuge," Clinical Chemistry, vol. 18, no. 6, pp. 499-502, 1972.

[23] A. Katz, S. S. Nambi, K. Mather et al., "Quantitative insulin sensitivity check index: a simple, accurate method for assessing insulin sensitivity in humans," Journal of Clinical Endocrinology and Metabolism, vol. 85, no. 7, pp. 2402-2410, 2000.

[24] Team RDC, R: A Language and Environment for Statistical Computing, R Foundation for Statistical Computing, 2014.

[25] M. C. Carr, "The emergence of the metabolic syndrome with menopause," The Journal of Clinical Endocrinology \& Metabolism, vol. 88, no. 6, pp. 2404-2411, 2003.

[26] W. R. Hazzard, "Atherogenesis: why women live longer than men," Geriatrics, vol. 40, no. 1, pp. 42-54, 1985.

[27] M. Singh, S. H. Chin, D. Crothers, P. Giles, K. Al-allaf, and J. M. Khan, "Time trends of gender-based differences in lipid goal attainments during secondary prevention of coronary artery disease: results of a 5-year survey," American Journal of Therapeutics, vol. 20, no. 6, pp. 613-617, 2013.

[28] R. K. Reibis, K. Bestehorn, D. Pittrow, C. Jannowitz, K. Wegscheider, and H. Völler, "Elevated risk profile of women in secondary prevention of coronary artery disease: a 6-year survey of 117,913 patients," Journal of Women's Health, vol. 18, no. 8, pp. 1123-1131, 2009.

[29] I. Gouni-Berthold, H. K. Berthold, C. S. Mantzoros, M. Böhm, and W. Krone, "Sex disparities in the treatment and control of cardiovascular risk factors in type 2 diabetes," Diabetes Care, vol. 31, no. 7, pp. 1389-1391, 2008.

[30] T. J. Wang, M. G. Larson, D. Levy et al., "Impact of age and sex on plasma natriuretic peptide levels in healthy adults," The American Journal of Cardiology, vol. 90, no. 3, pp. 254-258, 2002.

[31] A. Clerico, M. Fontana, S. Vittorini, and M. Emdin, "The search for a pathophysiological link between gender, cardiac endocrine 
function, body mass regulation and cardiac mortality: proposal for a working hypothesis," Clinica Chimica Acta, vol. 405, no. 1-2, pp. 1-7, 2009.

[32] S. Maffei, S. Del Ry, C. Prontera, and A. Clerico, "Increase in circulating levels of cardiac natriuretic peptides after hormone replacement therapy in postmenopausal women," Clinical Science, vol. 101, no. 5, pp. 447-453, 2001.

[33] C. S. P. Lam, S. Cheng, K. Choong et al., "Influence of sex and hormone status on circulating natriuretic peptides," Journal of the American College of Cardiology, vol. 58, no. 6, pp. 618-626, 2011.

[34] W. B. Kannel, "Metabolic risk factors for coronary heart disease in women: perspective from the Framingham Study," American Heart Journal, vol. 114, no. 2, pp. 413-419, 1987.

[35] R. M. Krauss, "Lipids and lipoproteins in patients with type 2 diabetes," Diabetes Care, vol. 27, no. 6, pp. 1496-1504, 2004. 


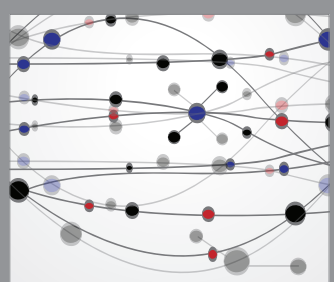

The Scientific World Journal
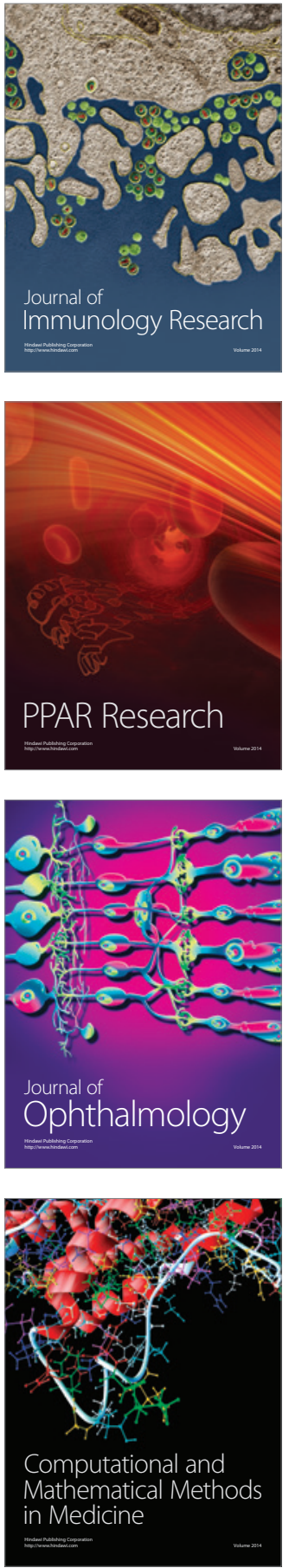

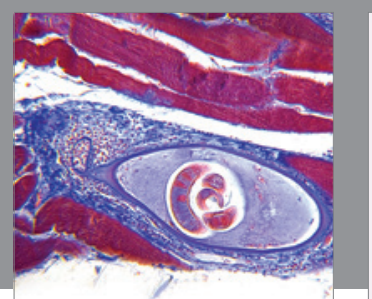

Gastroenterology Research and Practice

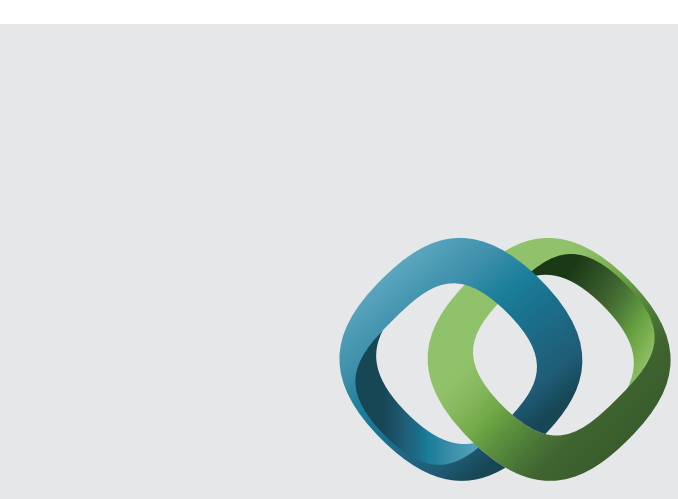

\section{Hindawi}

Submit your manuscripts at

http://www.hindawi.com
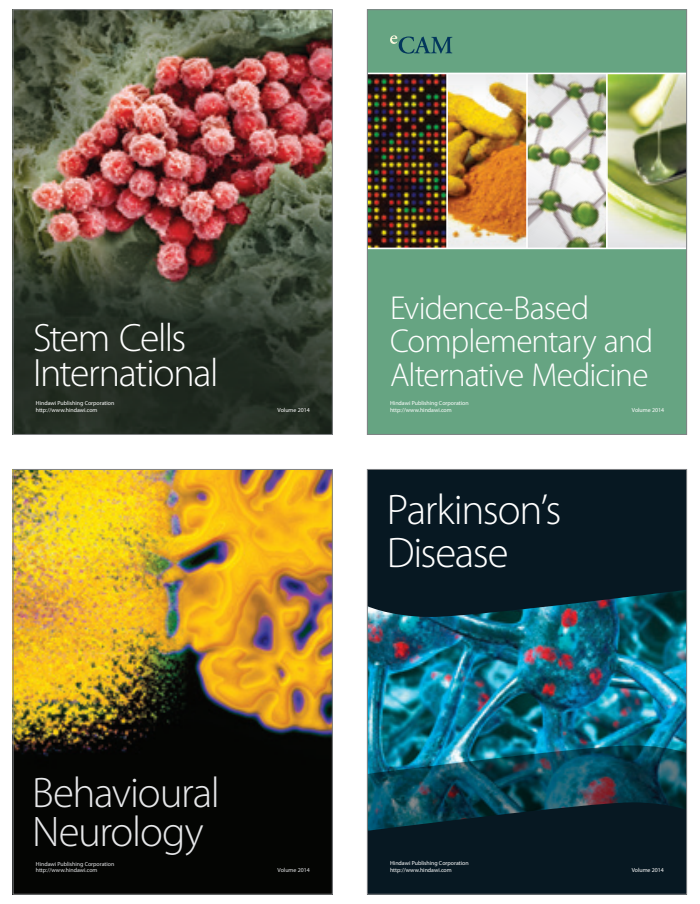
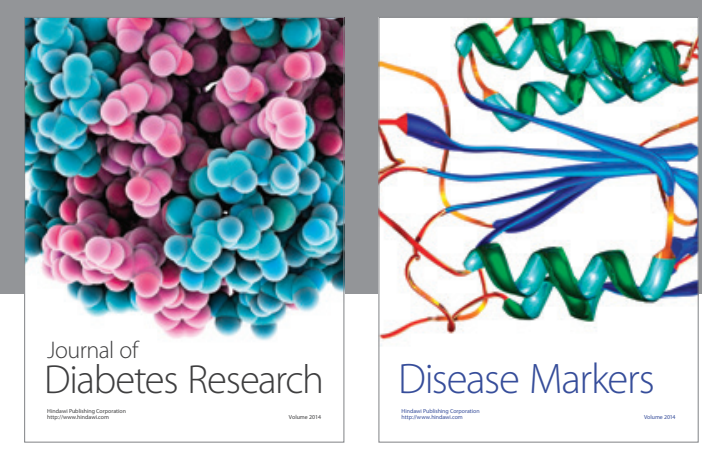

Disease Markers
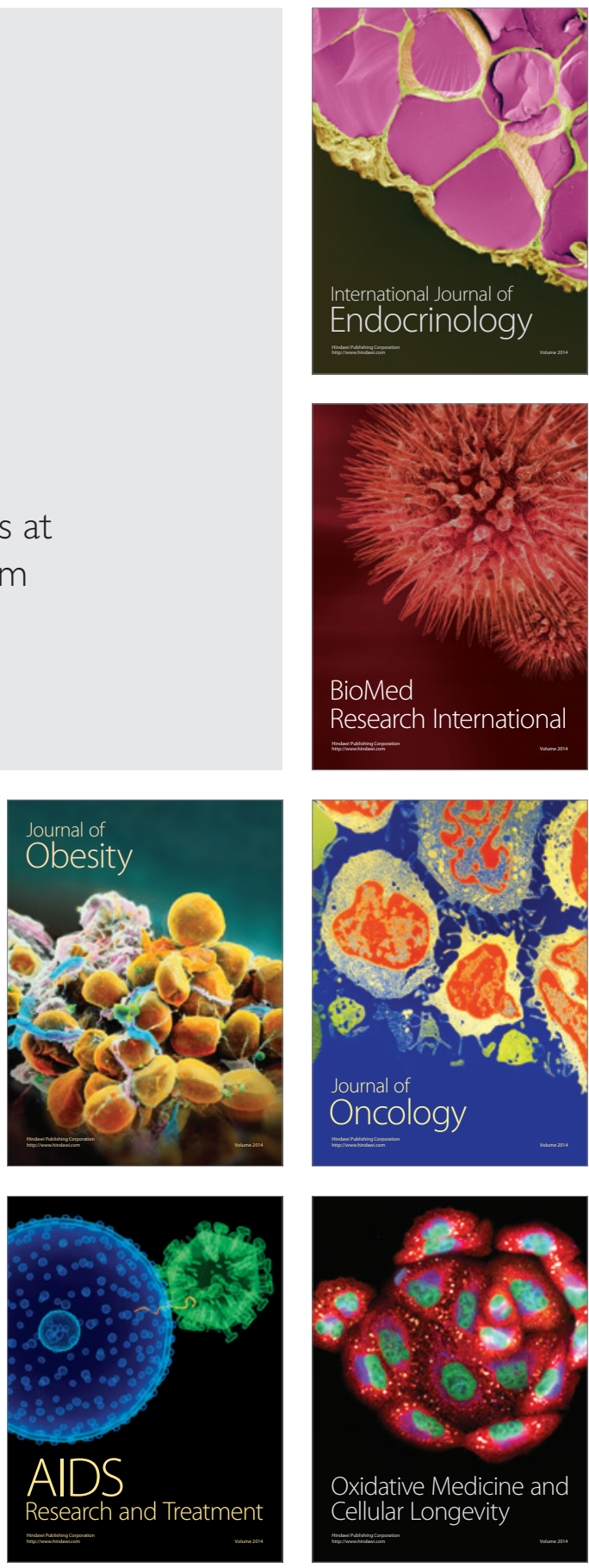